\title{
Networks, Hierarchies, and Markets: Aggregating Collective Problem Solving in Social Systems
}

\section{Citation}

Lazer, David, Ines Mergel, Curt Ziniel, and Michael Neblo. 2009. Networks, Hierarchies, and Markets: Aggregating Collective Problem Solving in Social Systems. HKS Faculty Research Working Paper Series RWP09-017, John F. Kennedy School of Government, Harvard University

\section{Published Version}

http://web.hks.harvard.edu/publications/workingpapers/citation.aspx?Publd=6694

\section{Permanent link}

http://nrs.harvard.edu/urn-3:HUL.InstRepos:4481607

\section{Terms of Use}

This article was downloaded from Harvard University's DASH repository, and is made available under the terms and conditions applicable to Other Posted Material, as set forth at http:// nrs.harvard.edu/urn-3:HUL.InstRepos:dash.current.terms-of-use\#LAA

\section{Share Your Story}

The Harvard community has made this article openly available.

Please share how this access benefits you. Submit a story.

\section{Accessibility}




\author{
Faculty Research Working Papers Series
}

Networks, Hierarchies, and Markets: Aggregating Collective Problem Solving in Social Systems

\author{
David Lazer \\ John F. Kennedy School of Government - Harvard University \\ Ines Mergel \\ Maxwell School of Citizenship and Public Affairs, Syracuse University \\ Curt Ziniel \\ Department of Political Science, University of California, Riverside \\ Kevin Esterling \\ Department of Political Science, University of California, Riverside \\ Michael Neblo \\ Department of Political Science, Ohio State University
}

June 2009

RWP09-017

The views expressed in the HKS Faculty Research Working Paper Series are those of the author(s) and do not necessarily reflect those of the John F. Kennedy School of Government or of Harvard University. Faculty Research Working Papers have not undergone formal review and approval. Such papers are included in this series to elicit feedback and to encourage debate on important public policy challenges. Copyright belongs to the author(s). Papers may be downloaded for personal use only. 


\title{
Networks, hierarchies, and markets: Aggregating collective problem solving in social systems
}

\author{
David Lazer \\ Kennedy School of Government, Harvard University \\ Ines Mergel \\ Maxwell School of Citizenship and Public Affairs, Syracuse University \\ Curt Ziniel \\ Kevin Esterling \\ Department of Political Science, University of California, Riverside \\ Michael Neblo \\ Department of Political Science, Ohio State University
}

\begin{abstract}
How do decentralized systems collectively solve problems? Here we explore the interplay among three canonical forms of collective organization-markets, networks, and hierarchies — in aggregating decentralized problem solving. We examine these constructs in the context of how the offices of members of Congress individually and collectively wrestle with the Internet, and, in particular, their use of official websites. Each office is simultaneously making decisions about how to utilize their website. These decisions are only partially independent, where offices are looking at each other for lessons, following the same directives from above about what to do with the websites, and confront the same array of potential vendors to produce their website. Here we present the initial results from interviews with 99 Congressional offices and related survey of 100 offices about their decisions regarding how to use official Member websites. Strikingly, we find that there are relatively few efforts by offices to evaluate what constituents want or like on their websites. Further, we find that diffusion occurs at the "tip of the iceberg": offices often look at each others' websites (which are publicly visible), but rarely talk to each other about their experiences or how they manage what is on their websites (which are not publicly visible). We also find that there are important market drivers of what is on websites, with the emergence of a small industry of companies seeking to serve the 440 Members. Hierarchical influences - through the House and through the party conferences-also constrain and subsidize certain practices.
\end{abstract}

Institutional Entrepreneurship, Collaborative Learning, Information Technology, Congress, Diffusion, intra-, inter- and extra-organizational influence, online practices.

Acknowledgements: We gratefully acknowledge the support of NSF grant No. 0429452. Any opinions, findings, and conclusions or recommendations expressed in this material are those of the author(s) and do not necessarily reflect the views of 
the National Science Foundation (NSF). Updates on the progress of the research will be reported at www.ksg.harvard.edu/netgov. 
How do we collectively solve problems? How do systems balance the dissemination of information and incentives to innovate? This paper builds on the "parallel problem solving" framework developed in Lazer and Friedman (2007a) to study the social structure underlying exploration and exploitation in decentralized systems (see March 1991). Lazer and Friedman, using simulation methods, focusing on the role networks play, highlighted the potential trade off between dissemination of information about innovation and the probability that innovation will occur. Here we examine a particular decentralized organizational setting (the House of Representatives), where the constitutive elements (Member offices) are dealing with a particular novel problem - how to manage their websites. Our objective is to understand the different roles that three organizational archetypes play in organizing and aggregating collective problem solving in this setting: networks, markets, and hierarchies.

We find that all three archetypes capture some of the processes driving the aggregation of collective problem solving with Congress. We find that there are both attentional and interpersonal networks through which a great deal of information flows; that there has developed a vigorous market for web services on the Hill; and that both the technical infrastructure and party system also create substantial capacity for problem solving. Strikingly, however, we find that there is relatively little evaluation of what actually works in terms of the ultimate objectives of the websites-e.g., what do constituents what out of the website, what do visitors to the website look at.

\section{Parallel Problem Solving}

This paper builds on the parallel problem solving (PPS) framework (see Lazer and Friedman forthcoming). In the PPS framework, it is assumed that there is a set of agents interacting with the environment, attempting to solve the identical problem. The payoffs to particular solutions are not directly interdependent - the success of one actor does not directly affect the success of other actors. It is assumed, however, that there is an informational interdependence. 
Actors adapt through two mechanisms: experimentation and emulation. Experimentation involves learning through interactions with the environment. Actors may, for example, try different solutions, and discover some work better than others. Emulation involves learning from other actors. In the original Lazer and Friedman paper, it was assumed that actors could evaluate their success and the success of the actors they could see. In a broader framing of PPS we take here, we make no assumptions that actors can fully evaluate either their own or other actors' success. Figure 1 offers a schematic representation of the PPS framework, where the squares are the actors, the lines connecting them to the environment represent the flow of information actors receive from the environment, and the lines connecting the agents the flows of information among actors.

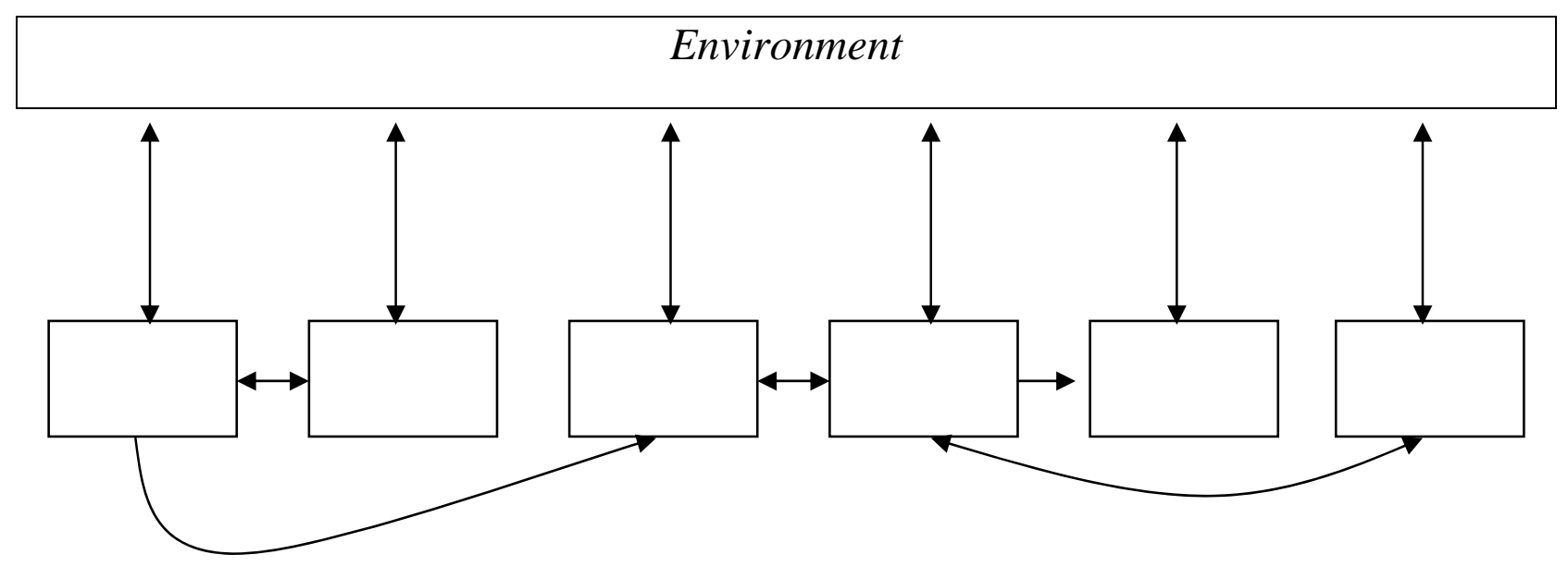

Figure 1: Parallel problem solving framework

PPS offers an ideal-type, but one which many systems approximate, including government agencies dealing with similar problems, state governments, individuals in an organization, and, in the case we examine here, the offices of members of Congress. As with any framework, all of these examples deviate somewhat from the ideal case. Thus, for example, the agents involved may be dealing with similar not identical problems (limiting the informational relevance of third party experiences), and there is some degree of interdependence of payoffs (e.g., members of Congress in the same party have an interest in each other's success).

This construction is explicitly multi-level, with analytic foci at both the individual and collective level. In fact, what may be good for the individual may not be good for the system because the more effective information dissemination, the closer to the ideal of a public good 
information created through experimentation becomes, resulting in a collective underinvestment in information (the "tragedy of the network" - see Lazer and Friedman 2007b).

This construction highlights two key questions: first, how does novel information enter the system? And second, how does that information flow through the system?

PPS bares a close relationship to the vast diffusion of innovation literature. Adoption of innovative organizational practices is defined as "the process by which an innovation is communicated through certain channels over time among the members of a social system" (Katz/Levin et al. 1958; Rogers 1995:5). This describes a special type of communication in which the messages are concerned with new ideas for organizational practices; it denotes the flow or movement, sometimes also called "spread," of an innovation from a source to an adopter by means of communication and information dissemination (Strang/Soule 1998:266).

Diffusion studies have a long history in different research fields. Classic studies include Ryan \& Gross's (1943) analysis of the diffusion of hybrid corn, Hargerstrand's (1967) study of the diffusion of the telephone and tests for tuberculosis involving the destruction of cattle in rural Sweden, and the findings of Coleman et al. (1966) about the diffusion of drug prescriptions among physicians in US cities. These studies are focused on the spread of an innovation through communication channels, the role of mass media and professional change agents, and interpersonal interactions among the adopters.

Closely related to both PPS and the diffusion literature is the research in economics on information cascades (e.g., Bikhchandani/Hirshleifer et al. 1992). This vein of research assumes that actors each receive independent signals about the state of the world, where adoption decisions (but not success/failure) can be seen. The essential insight is that under certain circumstances the private signals (which are assumed to be on average correct) may be overwhelmed by the public signals of visible adoptions, leading to potentially suboptimal outcomes.

PPS differs in one key regard from both the diffusion and cascade literatures, which is in its assumption that actors actively engage with the environment. Thus, in contrast to most of the diffusion literature, the probability of the emergence of an innovation is explicitly incorporated 
into the framework; and in contrast to the cascade literature, the focus is on the aggregation of problem solving, not the aggregation of information.

Here we explore the role that three institutional mechanisms for organizing collective human effort play in the aggregation of problem solving: markets, hierarchies, and networks (cf Powell 1990). Networks were the exclusive focus of Lazer and Friedman (2007a), where the key question was whether well connected networks improved the aggregation of problem solving. The essence of the network perspective to the aggregation of problem solving is understanding the balance at both the individual and collective level between experimentation and emulation. Further, to some extent, experimentation and emulation are substitutes. The more opportunities there are to copy others, the less the incentive to produce a new solution.

The emulation process in networks is driven by visibility. The network provides the conduit for emulation-A can emulate B only if they see what B is doing. Visibility depends on the nature of the innovation. Some "innovations," by their nature, are publicly visible. This is part of a larger pattern of systems where units can cheaply observe or refer to particular other units, where that link requires no reciprocal effort. Other examples include: the linkage structure of the world wide web; and the reference structure of scholarly articles. This observation structure may be viewed as an attentional network, where edges are directed from the actor who pays attention to the actor that receives attention.

With publicly visible innovations, one then has to understand what the drivers of attention are. In a world where everything is visible, collective attention may still be focused on a small subset of actors. Other innovations are only accessible through direct engagement, typically through interpersonal networks, by which we mean the presence of some set of ongoing relationships within a set of individuals.

While not the focus of this paper, as a general proposition we would note that attentional networks likely have distinctive topographies, with, for example, constraints on the number of outgoing ties and no constraints the number of incoming ties. Thus, for example, while some academic papers have many thousands of references to them (and most have just a handful), no academic papers contain thousands of references. By contrast, there are likely significant upper limits in terms of the number of reciprocal friendships an individual can sustain. 
There is no well developed literature on "network failure" as there is on market failure. By failure, we simply mean that there known conditions under which the institutional mechanism in question will produce collectively suboptimal outcomes. In this context, we point to a few obvious ways that networks may fail. First, as Lazer and Friedman (2007a) highlight, networks that are effective at disseminating information may prematurely eliminate diversity of solutions in the population, resulting in lower long run performance. Second, because networks rely on reciprocity to sustain them, and many settings do not have a numeraire good (such as money), there may be many exchanges that are welfare improving that cannot happen. For example, if A has information that will make B \$100 better off, and B has nothing that will make A better off, and there is some cost greater than 0 but less than $\$ 100$ to $\mathrm{A}$ to transfer that information, then the transfer may not take place, despite the fact that it would improve collective welfare. In a world with an unequal distribution of information (and other resources), there is no reason to expect that reciprocity can produce something close to the collective optimum in welfare. Finally, there may simply be a scale required to the production of information that no single actor in a decentralized, networked world, can sustain. To take an extreme example, it takes a very large scale to produce a new passenger jet. A decentralized system of the same size Boeing simply might not be able to create the same outcome.

Markets and hierarchies each provide mechanisms for creating scale in problem solving. Hayek, and those who have followed him in economics, highlights the role of markets in aggregating information in decentralized systems. With respect to problem solving in decentralized systems, the role of the market (we would argue) is exactly the opposite: markets offer an institutional mechanism to centralize functions in systems that are otherwise decentralized. That is, assume that there are 100 actors in a system, and that production of an innovation requires some scale greater than a single actor. This scale can either be achieved through the merging of actors (possible in the private sector, and often impossible in the public), or through the merging of particular functions in a smaller number of actors. This is one of the driving forces behind outsourcing - that the entities to whom services are outsourced can achieve a scale (because they serve multiple customers) impossible if the service were produced in house. 
There are several ways that markets can fail in the production of information. If emulation is easy, then the incentive to invest to produce information may disappear, because it will be impossible to make rents off of that investment. There are two reasons why emulation might not be easy. The first is that there may exist intellectual property rights-prohibitions on emulation. Second, effective emulation may require expensive knowledge transfer, for example, because there is a strong learning by doing component in the accumulation of knowledge (hence the difficult in transferring expertise in, for example, tennis). These two factors may be combined, e.g., through noncompete clauses that prohibit employees taking jobs with competitors, creating a de facto right in the employees knowledge by the employer.

The presence of intellectual property rights and expensive knowledge transfer may, in turn, create their own forms of market failure-through the creation of a monopoly, which, generally, will create a price for the good that is too high.

Hierarchies resolve the scale issue by, essentially, removing (at least partly) one of the premises of PPS: decentralized decision making. Hierarchies do this in two ways. First, they can consolidate systemic production, potentially resolving the scale issue. Second, they can authoritatively constrain or mandate particular behaviors. Thus, in principle, where reciprocity cannot sustain a collectively welfare improving exchange between A and B, in an hierarchy, A can be forced to help B.

Hierarchies, of course, have their own dysfunctions. First, by consolidating production internal to the system, hierarchies do not eliminate the problems of monopoly. Instead, they create an internal monopolist that may have the same issues around pricing (or efficiency) that a monopolist in the market would have. Second, a world where agents have subtly different problems they are wrestling with creates an enormous informational challenge for the apex of the hierarchy. Effectively intervening in a fashion to force information exchanges in every case that they would enhance the welfare of the system is a similar impossibility.

As a general proposition, all of these organizational forms coexist, in different degrees. For example, if you look at one of the classic studies of diffusion-tetracycline (Coleman et al. 1966) — all three mechanisms were at work within the system. At its core, this was a study of the decentralized decision-making of doctors, whose objective was to take care of their patients. Coleman and collaborators focused on how doctors learned through their network whether 
tetracycline was effective. However, not too far in the background was the fact that there was a market for drugs, with powerful intellectual property rights, which facilitated the creation of the drug in the first place, and which created an incentive to share information about the drug (in fact, a recent re-analysis of the Coleman data suggest that the network had little effect on behavior once one controlled for who was targeted for marketing). Further, in the background was a legal and regulatory regime that (1) protected those intellectual property rights, and (2) approved of the drug for circulation.

Our objective is to use the emergence of a particular "problem", the use of the Internet by members of Congress, to explore how these mechanisms for organizing collective problem solving coexist. We now turn to a discussion of our methodology.

\section{METHODOLOGY}

\section{Case selection and context}

The empirical focus of this paper is on the use of the official websites by Congressional offices. There are two primary reasons that we chose this as a setting in which to study PPS. First, is the novelty of the medium, and second is the decentralization of the management of Congressional offices. We discuss each in turn.

Novelty of the medium: Every member of the House currently has an official website. These websites present a virtual face of the member to the world, and most notably, to his/her constituents. Below are screenshots of the website of a particular Members: Robert Brady.

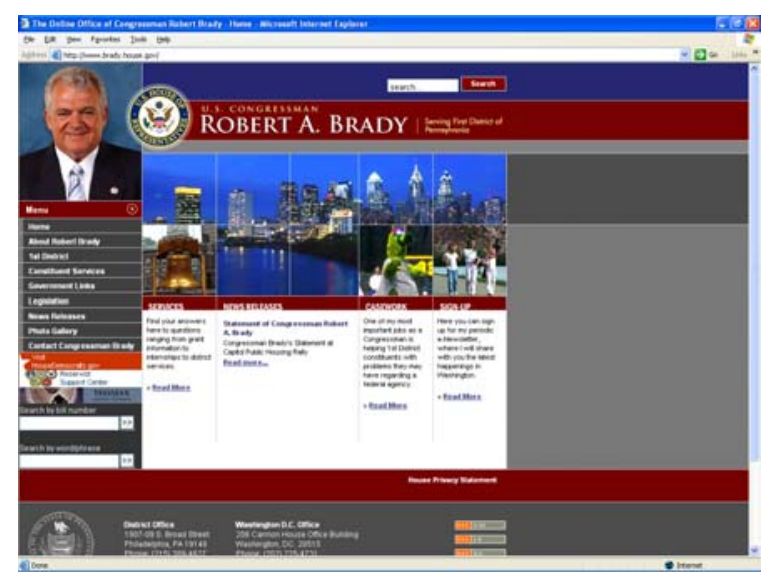

Figure 2: Sample Congressional website 
Given the wide-reach of the Internet, these official websites offer a potentially powerful means to communicate with constituents and the public in general. However, it is also a relatively novel medium for communication-as of a decade ago, only about half of the Members even had a website, and a few years before that the World Wide Web didn't even exist. A casual perusal of websites suggests some degree of convergence, but also nontrivial variation and experimentation. From our perspective, the learning about the power of the medium is still fresh. This provides the opportunity for us to examine this learning process.

Decentralized nature of Congress: Congressional offices can be considered as 440 small, functionally identical, and independent public organizations (Salisbury/Shepsle 1981). As one staffer we interviewed stated: “There're 435 small businesses here, and each 'CEO' can do what they want."1 There are some House rules that limit how offices can use their websites, but within those constraints, Congressional offices collectively come close to matching the assumption in the PPS framework that the units of analysis are independent decision makers.

There is clearly some interdependence of payoffs in the success of Members-e.g., Democrats have a stake in the success of other Democrats and in the failure of Republicans, and vice versa. However, the payoff a particular Member gets out of the effective use of the official website by a specific other Member is surely fairly tiny.

We would also note that Members confront somewhat different challenges in communicating with constituents. The needs of a Member from a rural Colorado district differs from the needs of a Member representing Manhattan. However, all offices are operating under similar resource constraints, and similar desires to satisfy constituents and portray a positive image of the Member. Further, much of this heterogeneity is visible both to the offices and to the researcher; and one key subsidiary question we pursue is how this heterogeneity affects the search process.

The use of the Internet by Congressional offices thus offers a good fit with the PPS framework, constituting a large set of essentially identical organizations that are in a position to learn from one another. Congressional offices thus provide a "sensitive" instrument with which to examine social learning processes.

\footnotetext{
${ }^{1}$ There are 435 voting Members, and five non-voting delegates.
} 


\section{Data Collection}

We conducted interviews with the Congressional staff person who had primary responsibility for the official Member website of 99 Members of Congress. These offices were recruited by our research partner, the Congressional Management Foundation (CMF). The CMF is a small nonprofit devoted to the improvement of the management of Congressional offices that has existed for approximately the last 30 years. The sample was constructed purposively to be roughly reflective of the body as a whole, but, due to the vagaries of who was willing to cooperate, is biased toward affluent urban districts, Democrats, and offices with above average websites (Table A1 in the appendix compares key descriptives for the body as a whole to the sample). In our analyses below we examine whether our observations are robust across subsamples, focusing, in particular, on under-represented strata. We note where we find significant deviations across subsamples.

We conducted semi-structured interviews, where each interview lasted about 45 minutes. The interviews were transcribed and each statement in every interview coded in an iterative process using the qualitative data analysis program NVivo 2 (QSR International Pty. Ltd. 19902002).

At approximately the same time we conducted the interviews we also conducted a survey of the Communications Directors in House offices. This survey was more broadly about communication strategy, but did include a few items regarding where offices got information about what to do with their websites. We received 100 responses out the 440 Members, for a response rate of $23 \% .^{2}$ In future iterations we will examine the selection and sampling issues that may affect estimates of population parameters; in the current version we simply report sample means (the numbers we report should therefore be interpreted with caution).

Here our core question is to understand the ways in which Congress pools the experiences of Congressional offices vis-à-vis the use of the Internet. We break this down into three subsidiary research questions:

(1) How do offices learn about which of their practices are successful and which are not successful?

\footnotetext{
${ }^{2}$ There was an overlap of 53 offices between our two samples.
} 
(2) How do offices learn from other offices? In particular, how do they learn which of the practices of other offices are successful and which are not successful?

(3) What institutions outside a offices have a major impact on aggregating information, provide incentives for certain practices, and set the normative environment?

The first question focuses on feedback from the environment-e.g., do offices gather data on constituent preferences? Do they track what information surfers look at, and what proportion of hits are from the district? This information, potentially, feeds back into the broader informational ecology of Congress, through the retention/non-retention of certain practices and content, as well as informal interpersonal conveying of collected experiences between offices. Finally, what role in aggregating information do the institutional and organizational structures both within and outside of the institution built to support Members?

\section{RESULTS}

Our analytic interest is how the system pools together the experiences of various offices' use of their official websites. Viewing the Member's office as the relevant locus of decisions about how to use the website, we split our analysis up into (1) environmental feedback; (2) inter-office (network) flows of experiences; (3) market-driven influences on decisions regarding websites; and (4) top-down drivers of practices.

\section{Environmental feedback}

The first component of PPS framework is learning from the environment. Specifically, in this case, do offices find out from their own experiences what works and does not work through feedback from their constituents? The Internet offers particular promise for learning from the environment, because it is possible to track with some detail what visitors to the website are doing (e.g., number of hits, pages visited, referrers, etc.).

We therefore evaluate two questions: to what extent do offices (1) proactively assess what their target audience for the website (generally, constituents) wanted from the website; and (2) ex post assess whether their website was hitting the target?

There was strikingly little effort by offices to proactively assess what constituents wanted. In fact, only two out of 99 offices (both representing districts with above average 
educations and incomes) indicated any type of research into what their constituents wanted, as one of them describes:

We ... sent out a survey to about 40,000 constituents... asking whether podcasting was a feature they'd use, and whether televideo conferences, online town halls, all [that] stuff, what did they want. What should our very limited resources be devoted to. The website was one of the top ones, without a doubt. Podcasting, in contrast, had a very limited response...

The lack of active proactive research on what constituents want is, perhaps, unsurprising, given the expense of surveys, focus groups, etc. The monitoring of the use of the website, however, is much cheaper. Readily available data which is usually automatically collected include: number of unique visitors and page views; what parts of the website are viewed; the approximate geographic location of each visitor to the website; who is linking to the website; where traffic to the website is coming from. It should therefore be easy to produce regular reports indicating how much traffic the website is getting, and from what part of the district, looking at which web pages. It is therefore surprising that few offices reported looking regularly (or even recently) at these data (although the offices, when asked about this, very often noted this lack with regret). Even those offices that reported tracking what parts of the website get hits did not examine the data carefully, as this one exchange highlights:

[Q: Do you look at what pages on your website get the most hits?]

We do.

[Q: Do you do anything with that?]

We used to do it more, I actually need to find out. (Sigh)

From another office:

We don't monitor as closely as I think would be helpful in terms of the Web traffic. We do an email program that runs separately that I can tell what links people are clicking on, but we don't often go back to the website to see, okay, this page was the most visited.

Therefore we derive the first observation:

Observation 1: $\quad$ Offices seek and receive relatively little systematic feedback from constituents regarding their websites.

\section{Networks}

Do Congressional offices learn from each other what to do with their websites? The relative similarity of the situations of Members creates substantial potential for informational 
externalities. This potential of cheaply copying the practices of other Members is not lost on harried staff, as one observed:

I was not in the business of trying to reinvent the wheel. I just wanted to... go out and steal the best ideas I could from other people.

There are two pathways by which offices may affect each other: interpersonal communication and passive observation. The particular set of practices we are studying are, by their very nature, in significant part public. Member websites are public and therefore observable to all other offices, and viewing what particular other offices are doing is quite cheap and convenient. This is a contrast to many other practices, such as the use of particular types of databases to manage correspondence, which are essentially invisible to outsiders. We also note that the capacity to observe is finite-for example, in this case it is only (generally) possible to observe some subset of other Member websites. What is interesting about Member websites is that while one component is easily observable (the actual website), there is much information that is not visible, such as the experiences of the office (e.g., failed experiments that are no longer on the website) and the management processes underlying what is on the website. These experiences are only accessible interpersonally - by talking to someone in another office, and engaging in a give and take about their management practices and experiments. The following interviewee illustrates search both through observation and communication:

We looked at every single website.... We probably had [a list of] the top 30 sites. I individually contacted every single one of those offices, and found out, who do you use for your website, who does the upkeep of it, who designed it, got all of the specifics of it...

Unsurprisingly, the vast majority of offices reported looking at other websites for insight. However, most interviews suggested that interpersonal interactions with other offices were pretty minimal; the following represents the typical response:

I didn't talk to other staff members. I definitely looked at other Members' sites very carefully and tried to see what, what they were doing that might work for us.

Notably, in the interviews, only one office reported talking extensively to other offices about internal processes (e.g., website design; how to get content on the website, etc.). Interpersonal 
communication was largely focused on identifying vendors, where the following two responses are typical:

We've looked at basically every other member site there is.... [W] picked out the ones we liked the best, and I contacted their staff, and we found out who their... vendor was.

I mean, I just talked to a bunch of my friends that are press secretaries basically. I just called them and said hey, who do you guys use, or, you know, is there anything you'd recommend? I really like your site, who did you use? Yeah, you know, basically word of mouth. [Name] did the same, our chief of staff. And he talked to some other chiefs of staff, in terms of cost and benefits, and customer service.

These last two quotes illustrate two different strategies for identifying who to talk to. The first relied on an extensive search of what was observable to guide personal contact. That is, the attentional network guided interpersonal information seeking. The second indicates a reliance on friends, that is, a particular type of interpersonal network, friendship, guided interpersonal information seeking.

In short, search largely takes place with respect to things that are publicly available-offices looking at each others' web practices, but not talking to each other frequently, and when they talk to each, rarely delving into issues beyond vendor-related issues. We do not have a definitive explanation for this. This may be partly because offices do not look at each other as prime sources of best practices, as two individuals explain:

[Q: Have you talked to other people around the Hill who are running their websites]

I haven’t really, because, to be honest with you, there aren't a lot of people who really know web design that well.

I looked around at most of, of the congressional websites on the web and most of them I kind of found to be relatively unimpressive. You know, I've often heard the complaint from web savvy people that congressional websites all look the same. And basically they look very average. They might have some information on them about what the member is doing, but as far as being visually appealing they just, can’t hack it with some of the big private sector sites.

Further, there may also something of a "not built here" mentality within offices, that a particular office is so idiosyncratic that lessons regarding management practices are unlikely be successful. As one individual states, “[E]very congressional office just runs... their organization... in their own way.” 
Unsurprisingly, only a tiny fraction of the individuals we spoke with reported looking at every other website in Congress. Where did offices focus their attention? Some staff reported randomly browsing other Members' websites. Many were more purposive, looking at websites that had received an award from the Congressional Management Foundation (see discussion regarding CMF below). A smaller group reported looking at salient other Members, e.g., from nearby districts, or of prominent Members:

We [looked] at all the neighboring congressional districts... as well as leaders in Congress...: Nancy Pelosi, the Hoyer site, Denny Hastert.... So we copied a lot of... the best ideas from other websites.

Another subset explored non-Congressional or non-governmental websites:

I researched other sites, both commercial, Hill, other government entities, other things in life and you know jotted down ideas... what I liked about certain things... There are two [that stand out]... One was Senator Kennedy's website. In fact his website was pretty solid at the time... the other was Wine Inspector, wineinspector.com. They don't have a lot of information on their homepage, it's easily navigable.

Figure 1 summarizes the distribution of network strategies we observed among the people we interviewed (based on a coding of their responses to our structured interviews). The heavy reliance on attentional networks - with $62 \%$ of interviewees indicating that they looked at other websites but did not talk to other offices about web practices-is striking, particularly given the close physical proximity of the population we are studying. 


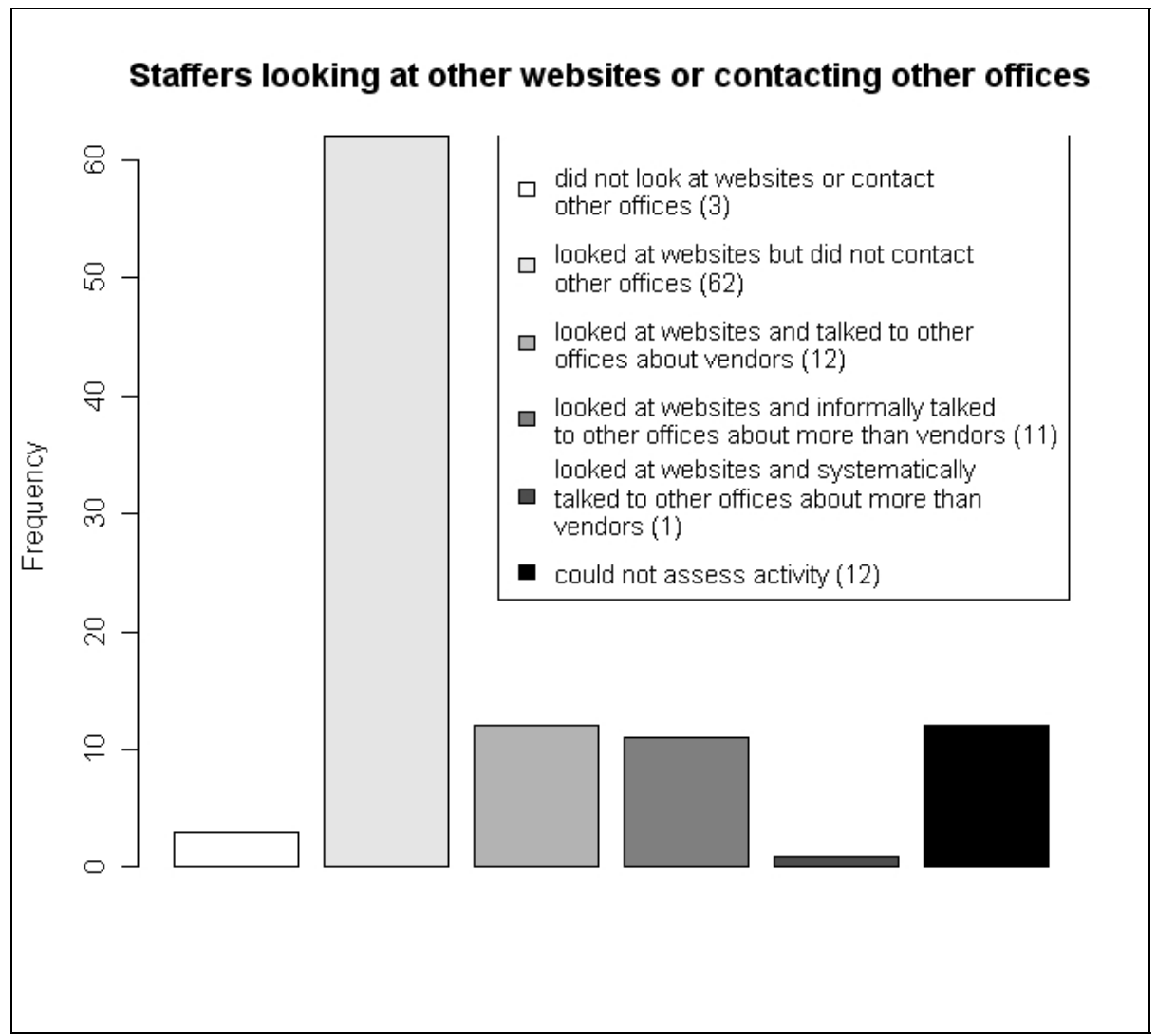

Figure 3: Search strategies

What are the determinants of the attentional network? The interviews suggest that proximity of district plays a role, and that the websites of particular Members, either because of the prominence of the Member, or because the website has been identified as particularly good. In the survey, we queried respondents about websites that they thought were "particularly good." Below are the websites that were identified more than once. We include the grade the website received in the "Gold Mouse” evaluations in 2006-winners from 2003 are italicized and winners from 2006 (announced after the interviews) are in bold. 


\begin{tabular}{lllrr}
\hline House & Last Name & First Name & Mentions & “Gold Mouse” grade \\
\hline Rep. & Kingston & Jack & 5 & 56.6 \\
Rep. & Pence & Mike & 5 & 48.9 \\
Rep. & Capps & Lois & 3 & 55.5 \\
Rep. & Honda & Mike & 3 & 98.1 \\
Rep. & Sanders & Bernie & 3 & 55.7 \\
Sen. & Clinton & Hillary & 3 & 69.1 \\
Sen. & Kennedy & Ted & $\mathbf{3}$ & 73.3 \\
Rep. & Barrow & John & 2 & 36.3 \\
Rep. & Blumenauer & Earl & 2 & 99.3 \\
Rep. & Boozman & John & 2 & 66.5 \\
Rep. & Conaway & Mike & $\mathbf{2}$ & 78.1 \\
Rep. & Fattah & Chaka & 2 & 49.9 \\
Rep. & Mack & Connie & 2 & 39.1 \\
Rep. & Musgrave & Marilyn & 2 & 46.6 \\
Rep. & Pryce & Deborah & 2 & 61.0 \\
Sen. & Hagel & Chuck & 2 & 50.7 \\
Sen. & Snowe & Olympia & $\mathbf{2}$ & 84.2 \\
\hline
\end{tabular}

Table 1: Congressional Members' websites viewed by others as particularly good (mentioned more than once, italics for Gold Mouse winners in 2003, bold for winners in 2006)

We are still in the process of evaluating what the drivers of receiving attention were. Clearly, for example, the set of sights listed received above average grades (62.9 versus 46.6 average for House). But the top three recipients of mentions were only mildly above average.

We also have an additional hint of the attentional process from when the "Golden Mouse awards" (there were three categories of winners: gold, silver, and bronze) from CMF were announced (see below). In the announcement that went to Member offices was a link to the list of award winners. Notably, of the total number of unique views of the Gold Mouse winners that first week, $24 \%$ of the hits in the first week went to the first url listed for the first gold medal winner listed out of ten winners, Rep Baird (they were listed alphabetically, not by score). These numbers suggest that, consistent with other attentional networks that have been studied (citation, web, etc.), there may be a heavily skewed distribution of in degree, driven by "winner takes all” self-reinforcing processes. 
We also have some hints at what the structure of the interpersonal network might look. We asked in the survey about what other offices they actively consulted with about their website. Only 52 offices were named (some respondents named multiple offices), so caution needs to be exercised in interpreting the data, but of those 52, 86\% were within the same party, and (when combined with 11 responses indicating the state delegation), 60\% were within the same state delegation. ${ }^{3}$ That is, interpersonal networks were significantly determined by party and stateand, based on our interviews, within state, proximity.

The emulation process begs the question: How do you know when you are looking at a good website? How do you know what is good practice on any website? There are virtually no available objective data on "success" or "failure”-e.g., approval/disapproval numbers from constituents, traffic. etc.. The general criteria used by staff was based on their own subjective experience of a particular website-as one individual stated: "[Y]ou know a bad one when you see it, and you know a good one when you see it too.” Further, the very presence of a feature on websites was an endorsement, as reflected in the reasoning of one staffer, "It was obvious everyone had a kids page, so we should definitely have a kids page...”

We would also note that sometimes practices were emulated simply because they solved a technical problem that an office was trying to solve, where presumably it was clear whether the solution in question worked or not. How this particular staffer, who was trying to figure out how to podcast, learned from another website is a case in point:

[T] here was no ... huge database of website to explain how to do [podcasting] on the Internet... The Committee on Government Reform figured out how to do it.... I just looked at their source code and... deciphered how that's done just by studying the code and understanding... the way it's structured.

Obviously, in the case of technical issues like this, it is easy to evaluate whether the solution of a particular website works (e.g., is it possible to play the file on an iPod). We can summarize our findings in the following four observations:

Observation 3: $\quad$ There is substantial emulation among offices of web-based features, but relatively little interpersonal communication of experiences.

Observation 4: $\quad$ Interpersonal networks are driven by party affiliation and geography.

\footnotetext{
${ }^{3}$ We also asked about who the Member was friends with, with similar results: of 90 "friends" named, $87 \%$ were same party, and $44 \%$ were same state.
} 
Observation 5: $\quad$ With respect to the emulation process, there was substantial variation in the thoroughness of offices in evaluating what others were doing.

Observation 6: $\quad$ There is relatively little basis for making objective evaluations as to the success of other websites.

\section{Markets}

Networks offer one mechanism for problem solving aggregation. Markets and hierarchies each offer different ways of pooling the problem solving abilities of actors. Information markets operate through the development of proprietary information, which is then monetized and sold. Hierarchies work through authority, and delegation of resources so that where scale is required, for example, decision making is centralized; and where context specific knowledge is necessary, decision making is decentralized. There are elements of both of these institutional archetypes in this setting. With respect to markets, a population of small companies that caters to the web needs of Congressional offices has emerged during the past years.

\section{The development of a market for web services}

Congressional offices are provided with a fixed budget, with which they have a fair degree of discretion. For some services, they therefore confront a build or buy decision-do they use staff to build a website, or purchase expertise to do so? Many offices have pursued the latter route, where a small cottage industry of firms have sprung up to offer web services to Members, where those firms are divided along Democratic and Republican (e.g., one firm is called "Right click") lines. Fifty-eight percent of the offices in our survey reported hiring an outside consultant, where the following were typical comments from interviews:

We had a great vendor that allowed us to change our whole front page. We could do a lot of things internally.

[O]ur vendor came up with the ideas for how exactly to make the tour pages, a lot of pages, automated. Because when we did that, that was almost five years ago, so that was when nobody was doing it. Now it's pretty standard to have some of those features.

The essential market logic behind the outsourcing of the website is that there are economies of scale in the problem solving process, where the unit cost of production of many websites is lower than the cost of producing a single website. In principle, the resulting surplus can be divided among profit, quality of website, and the ability to offer lower prices to offices. 
The effectiveness of the market in part rests on how well information can be protected. That is, if one vendor comes up with an innovative solution at some cost, and either offices or other vendors are able to copy that solution cheaply, there will be an underinvestment in innovation. In this particular domain, protection likely does not come in the form of intellectual property rights, but through the development of expertise that cannot be easily copied. However, that may still leave much relevant information protected, as highlighted by the statement of one clever staffer made use of vendor services in another way:

One of the things that I've seen several external consultants do to pursue our business is send us a review and a report on our website, sort of analyzed by their staff and saying this really should be updated, this really should be changed to meet the standard government configuration or whatever... I then see that and I say, okay, I think I'm going to implement these things myself.

In this case, the staffer is essentially free riding on the information produced by vendors

An additional issue with respect to vendors is that there will be a natural push from vendors to homogenize their products, because it is cheaper to offer a limited set of options, and in part because they are using off the shelf software designed for commercial purposes. Individual solutions for the different offices are then adaptation of the standard set of solutions plus a personalized configuration. As one individual noted:

Looking at some of the other companies, it sounded like they were trying to sell us more of like a template of like, what a website would look like, instead of... just completely designed to us, and how we wanted it.

Observation 7: $\quad$ Vendors play a critical role in aggregating experiences and standardizing practice through their provision of services to multiple offices.

\section{Hierarchies}

There are two layers of hierarchy within the House; one based on authority, and one based on power and resources. With respect to the former, the Committee on House Administration (CHA) sets budgets and rules constraining off-budget behavior (e.g., postings to official websites are limited in the last 30 days before the election). They also run the technical infrastructure of 
the House, House Information Resources (HIR). ${ }^{4}$ HIR provides essential IT support to the House. As part of that support is hosting of Member websites, as well as basic consulting on design, providing a number of templates for offices to choose from (at no cost). It is clear, however, that those templates are seen as somewhat constraining for some offices.

Part of the logic behind an hierarchical model of problem solving, like the market model, is that economies of scale in the provision of services can emerge. Production for offices may thus be consolidated at significantly lower cost. However, there is not a mandate that offices use HIR, creating a mixed model of production, through HIR, vendors, and self-production, where only $15 \%$ of offices in our survey reported using an HIR template.

As a point of comparison, interview responses suggest that while HIR is cheaper (free) private vendors generally provide more customized service and innovate faster than HIR is able to do.

[HIR] are more involved than we'd like them to be... for instance, someone found a typo on her [Member's] biography this weekend and I have to email them and wait for them to change it on that site. Also they just updated our content editor, which we have yet to make work... also, any time you want to put streaming media up, or, we can’t actually put streaming media up, but floor speeches, it has to go through them.

Thus, in short, the hierarchical model, in this setting, does not offer enough flexibility for many offices on the contrary it adds an additional layer of communication and interaction needs.

Observation 8: $\quad$ CHA plays a critical authority role in constraining what can be done with websites, and the technology infrastructure of the House, HIR, plays a marginal role in aggregating experiences across offices

The second layer of hierarchy is based on the party organization of Congress. Parties have no direct authority over what Members do with their websites. They do, however, have what we would label "problem-solving” resources. Earlier analysis of websites from 2003 suggested that Republicans had systematically better websites than Democrats (Esterling, Lazer, and Neblo 2005). This may have reflected a residual of the high priority that Newt Gingrich put on technology; further, JC Watts, a Republican Member from Oklahoma and part of the Republican leadership from 1998 to 2002, according to our informants, reportedly put a high priority on Member websites. Our interviews suggest that while the perception (especially among

\footnotetext{
${ }^{4}$ See the following website for additional information on CHA (http://www.cha.house.gov).
} 
Democrats) persists that Republicans put a high priority on Member websites, in fact the Democratic party made websites a high priority after Pelosi became minority leader. Thus, for example, many Democratic interviewees said that under Pelosi Democrats put a lot of energy into developing the website, HouseDemocrats.gov. Further, in an example of the resources of the parties, the Democratic caucus provided a customized analysis of every Democrat's website. One staff member described the consequences of this formal analysis as follows:

[A] couple of months ago the Democratic caucus... audited everyone's website. And told you what they thought was wrong with formatting, or telling you what rules you might have accidentally broken.... So that was a very... individualized report.

One office that was just starting out used the report to help them get their website off the ground and followed all the rules laid out by the Party:

[T]hey also gave a document of the highest scoring Democratic websites... the highest scoring was, [specific MC], and so I looked at his website and I thought it was very clear. And, as you can tell, ours is really similar. So I just worked with our HIR consultant, [name], a very good guy, and we created this.

The caucus thus plays a particular role in conveying to Members how to utilize new web-related innovations. The following interviewee works in the leadership, talks about their role in conveying lessons about online video and e-newsletters.

I was one of the first to get video up and running on my website.... I took the initiative.... We held a large meeting..., and I spoke and told them... it's really easy and everyone needs to do it.... And... at six months I was helping offices left and right copy that function.... We did it more recently with... e-newsletters... saying... you've got to do them. Such an easy, great, cheap way to reach all your constituents...

In 2006, the Democrats have also played a key role in pushing online townhalls, in part by centralizing and subsidizing online townhalls, in part by publicly demonstrating their by making them all available through the Democrats.gov website:

[T] he online town hall was done through the Democratic office. It's cost prohibitive for every office to have their own online townhall run on their own.... So... that's all centralized through the Democratic office.

Yeah, the e-townhall was pretty neat. We worked with the House Democratic Caucus and they helped us set up the proram that made it easy for us to post it. 
The Democratic caucus also played an important role in conveying the party's message via the web. Thus, for example, unsurprisingly, the audit that the Democrats conducted in part had a party-oriented tilt:

[The] survey was more focused on the party message than it was on the individual site. ... So... if we had a link to the Appropriation's Committee website, but not the Democratic Appropriations website, then we had points taken off because we should have been linking to the Democratic site...

The Democrats also more directly pushed for certain content and messages on Member websites. Unsurprisingly, the election was playing a big role during this period; a large number of Democratic offices expressed similar experiences with party leadership encouraging a unified message for the Fall election:

[T]he Democrats in July and August rolled out their message platform. It's called A New Direction for America... The main thing was one sheet, a description of what the new direction for America was. And the leader's office encouraged Members to put it up on the website....

[T] he leadership office sent out a template on the New Direction for America, and they made an announcement at our press secretary's meeting on Mondays, asking us to immediately put this up on our websites, because Leader Pelosi wanted all Democrats on message.

I thought that her [Pelosi's] office would just keep calling and telling me that I had to put it [New Direction template] up. (Laugh) But also, you know, it's party unity and people should see what the Democrats are standing for.

More generally, leadership plays a role in providing content to offices, as these comments makes clear:

I think it's gotten better over the past year. The Democratic leadership will offer suggestions, templates, links...

If you look at our website, there's something about veterans on there right now which came basically straight from Pelosi's office. There's also something about cuts to college loan programs, which is another email that was sent to us.

Strikingly, by comparison, the Republican leadership played a far less important role vis-a-vis their Members. Most staff were not negative about the conference, but even those who had apparent confidence that there was useful information to be found there did not look, as these two Republican staff convey: 
I never once spoke with [the Republican conference] about developing our website... I'm trying to think. I'm sure at some point in time they... provided examples of different types. I can't remember any specifics... but I'm sure if I did they would have given me great tips. But I didn't.

The] conference does a really good job... putting out... best practices.... [Q: To what extent have you gotten insights?] Not much.

Other staffers were less positive regarding what the party had to offer:

[T]he Republican Conference will send out stuff electronically to us.... I've had this conversation with [them], like ninety-five percent of what you send me is useless. It's too broad. It wouldn't work in my district anyway.

I think the Republican party's a little bit behind the Democratic party as far as... their commitment to technology... I don't know if they've been the leader that maybe [other staffer] and I feel that they should be. You know the Republican party being the leader and having its members really devote resources to internet communication... in my opinion, I think [other staffer] and I have really had to take it on ourselves, and it's our prior commitment to it, and our commitment to it that has made us really work hard on this, and not really our party's commitment to it.

In short, during the period of our interviews, it is clear that the Democrats were more proactive in providing both form and content for Member websites than Republicans, and that they had a real impact on Democratic websites. We would note that the relative importance of the party to Democrats as compared to Republicans in part reflects the relative popularity of Democrats as compared to Republicans during this period. In particular, while Democrats were trying to nationalize the election of 2006, Republicans were trying to keep races local. That is, identification with the Democratic Party was clearly a plus and with the Republicans a minus in 2006, and this almost certainly affected party strategy and Member receptiveness during this period.

Observation 9: $\quad$ The parties are aggregators of experience and supplier of web-related practices and content.

Observation 10: $\quad$ During 2006, the Democratic conference was substantially more effective at conveying practices and content to its Members than the Republican. 


\section{The Congressional Management Foundation}

The Congressional Management Foundation (CMF) also had a powerful impact on Web practices among Members, through its annual reports, and most importantly, through its "Golden Mouse" awards to the best websites. The golden mouse awards were based on a detailed set of criteria that CMF developed, in part based on focus groups it conducted, in part in consultation with staff on the Hill. The influence came through the construction of a set of norms as to what Members were supposed to do on their websites- the explicit identification of recommended practices. Thus, for example, many staff, given the responsibility for their Member's website, began by consulting the CMF report:

I basically took the CMF book from a couple years ago [to] see what the Golden Mouse winners were doing, and used those techniques.

[A]bsolutely. I've been to the CMF website and I've looked to see what their best practices are or what they say these members are doing correctly... to me, CMF, they're experts in what they recommend, and they look at every single house... website and they critique them. And to have that information that's available online for free, in my mind you'd be nuts not to look at it and use it and try to integrate that into your own website design.

The second theme that came up repeatedly was that the Golden Mouse award created a competitive environment among the offices to win the award in 2006, as the statements by the following three staff make clear:

I think, if we don't get at least a silver, it's off with my head. [laughter]... Powerful people, they like to compete with other old powerful people, and then show their little awards.

[T] he Congressman really wants to have a Golden Mouse.... That was part of the deal when he was going to hire me.

$[\mathrm{K}]$ nowing that, the whole Gold Mouse thing was going be coming around again I wanted to make sure that anything that we did for the Congressman was going to be very, very content rich, very, very content driven, and as one or two click friendly for a visitor as possible.

Therefore, CMF plays a double role in influencing the direction of what is perceived as good practice of Congressional websites. CMF sets the normative environment and their Golden Mouse award can also be seen as an intervention into the natural system. 
Observation 11: $\quad$ CMF plays a critical role in aggregating experiences through its reports, and in standardizing practices through its reports and sets into motion a competitive process with its Golden Mouse awards.

\section{DISCUSSION}

How do people collectively solve problems? We have examined the multiple types of institutional processes that govern the production and dissemination of a particular innovation among Congressional offices. Markets, networks, and hierarchies have their distinctive logics in organizing human activity, and each plays an important role in this setting. Offices can be seen as consumers of a service, where a small industry has arisen to supply their needs. Information about the innovation flows through the network - and within the multiple networks that exit, more the attentional than interpersonal. Multiple hierarchies govern office behavior, with both the administration of the House (through CHA) and the powers within the House (through the parties) playing key roles.

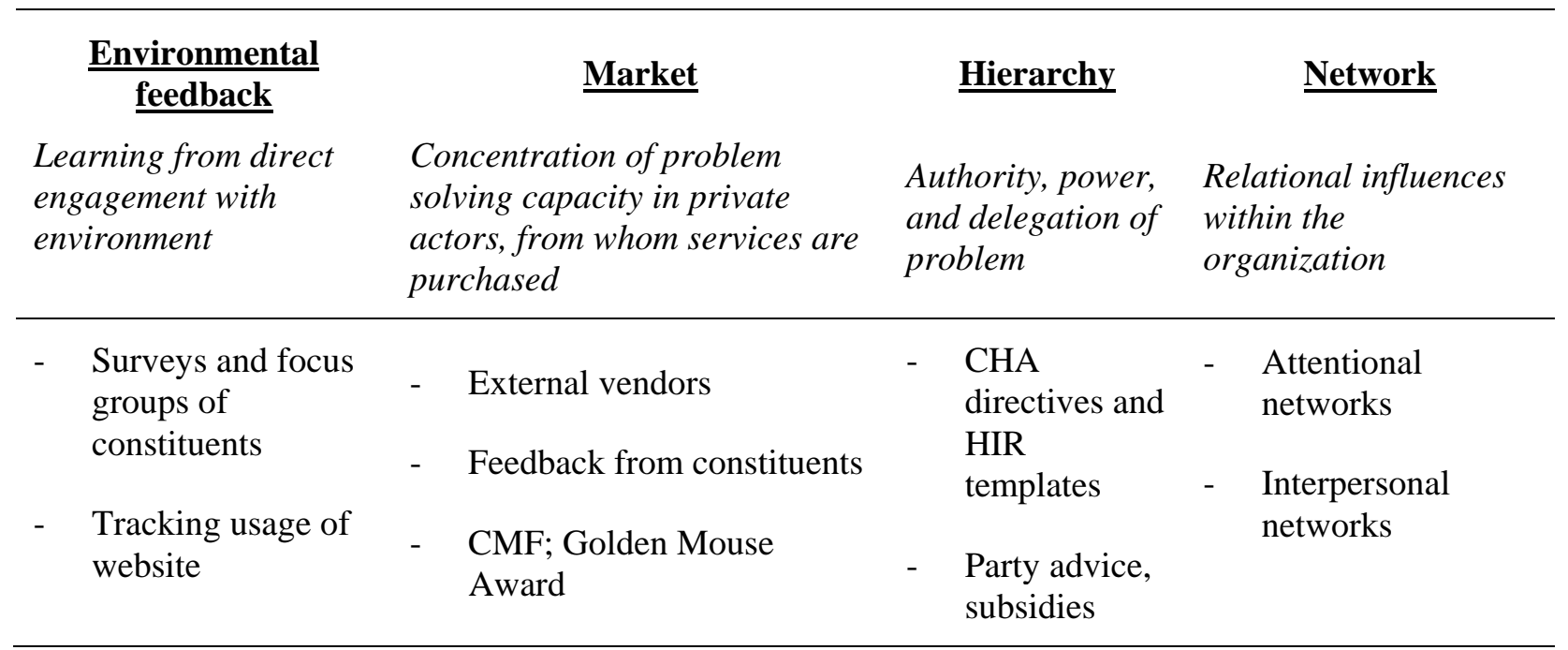

\section{Table 2: $\quad$ Factors influencing Congressional online practices}

These institutional logics interplay, with the interpersonal networks, for example, playing a key role in creating market share (through reputation) for the relevant firms; and the formal structure of the House clearly plays a key role in the emergent informal network.

While our main focus is on illuminating the presence of multiple institutional logics of innovation, a natural question is what the joint failings or success of the set up is. The above 
research highlights a number of troubling patterns. First, there is relatively little feedback into the system regarding success and failure. A necessary condition for effective problem solving aggregation within a system is for there to be significant amounts of experience with the environment to aggregate. From what we observed, there is rather little evidence with respect to what actually works. This, we would argue, reflects the dysfunctions of a decentralized system, where it is no single actor's interest to experiment. Second, there is relatively little interpersonal knowledge sharing regarding experiences within the institution. Instead, there is a reflective mimicry process, with subjective evaluation of others' visible practices. The net effect, perhaps, is a consolidation of practices, but without a strong foundation in the collective problem solving efforts of the constituent units of the system—-the Member offices. 


\section{Appendix A1}

\begin{tabular}{|c|c|c|}
\hline \multicolumn{3}{|c|}{ Comparison of Sample and House } \\
\hline & Sample & House \\
\hline MC Democrat & $62 \%$ & $47 \%$ \\
\hline MC Republican & $38 \%$ & $53 \%$ \\
\hline MC Female & $22 \%$ & $15 \%$ \\
\hline MC Freshmen & $11 \%$ & $9 \%$ \\
\hline MC term (average) & 5.65 & 4.5 \\
\hline Median district income & $\$ 51,050$ & $\$ 43,318$ \\
\hline $\begin{array}{l}\text { District \% urban } \\
\text { households (average) }\end{array}$ & $81 \%$ & $67 \%$ \\
\hline $\begin{array}{l}\text { District \% Bachelors } \\
\text { Degree (average) }\end{array}$ & $25 \%$ & $24 \%$ \\
\hline \multicolumn{3}{|l|}{ Region of country } \\
\hline Northeast & $15 \%$ & $19 \%$ \\
\hline South & $33 \%$ & $36 \%$ \\
\hline Midwest & $22 \%$ & $22 \%$ \\
\hline West & $29 \%$ & $22 \%$ \\
\hline
\end{tabular}




\section{BIBLIOGRAPHY}

Bikhchandani, S./D. Hirshleifer, et al. (1992). "A Theory of Fads, Fashion, Custom, and Cultural Change as Informational Cascades." The Journal of Political Economy 100(5): 992-1026.

Coleman, J. S./E. Katz, et al. (1966), Medical Innovation: A Diffusion Study, Indianapolis, Bobbs-Merrill.

Hagerstrand, T. (1967), Innovation Diffusion as a Spatial Process, Chicago, University of Chicago Press.

Katz, E./M. L. Levin, et al. (1958). "Traditions of research on the diffusion of innovation." American Sociological Review: 237-252.

Lazer, D., A. Friedman (2007b). "The Tragedy of the Network." Working paper.

Lazer, D., A. Friedman (2007a). "The Social Structure of Exploration and Exploitation." Administrative Science Quarterly.

March, J. G. (1991). "Exploration and Exploitation in Organizational Learning." Organization Science 2(1): 71-87.

Powell, W. W. (1990). "Neither market nor hierarchy : network forms of organization." Research in organizational behaviour. 12: 295-336.

QSR International Pty. Ltd. (1990-2002). QSR NVivo.

Rogers, E. M. (1995), Diffusion of innovations, New York.

Ryan, B/N. C. Gross (1943). "The diffusion of hybrid seed corn in two Iowa communities." Rural Sociology 8: 15-24.

Salisbury, R./K. Shepsle (1981). "U.S. Congressman as Enterprise." Legislative Studies Quarterly 6: 559-576.

Strang, D./S. A. Soule (1998). "Diffusion in Organizations and Social Movements: From Hybrid Corn to Poison Pills." Annual Review of Sociology 24: 265-290. 